Article

\title{
Study on Degradation of Benzothiazolium-Based Ionic Liquids by $\mathrm{UV}-\mathrm{H}_{2} \mathrm{O}_{2}$
}

\author{
Jianhui Gu ${ }^{1}$, Huimin Zang ${ }^{1}$, Shun Yao ${ }^{1}{ }^{\mathbb{D}}$, Xuejiao Wang ${ }^{2}$, Minghui Zhu ${ }^{2, *}$ and Hang Song ${ }^{1, *}$ \\ 1 Department of Pharmaceutical and Biological Engineering, School of Chemical Engineering, \\ Sichuan University, Chengdu 610065, China; jianhuigu00@sina.com (J.G.); 18702893626@163.com (H.Z.); \\ cusack@scu.edu.cn (S.Y.) \\ 2 School of Medical and Life Sciences, Chengdu University of Traditional Chinese Medicine, Chengdu 610041, \\ China; wangxuejiao1q@sina.com \\ * Correspondence: zhumh00@sina.com (M.Z.); hangsong@vip.sina.com (H.S.); Tel.: +86-28-6180-0260 (M.Z.); \\ Tel.: +86-28-8540-5221 (H.S.)
}

Received: 2 January 2020; Accepted: 26 January 2020; Published: 29 January 2020

\begin{abstract}
Ionic liquids (ILs) are considered to be a new type of solvent due to their low vapor pressure, some unique properties and are expected to be used widely in the following days. Given their water solubility, stable chemical structure, and biological toxicity, ILs probably reach aquatic environments and become long-term pollutants. We studied the fate of benzothiazolium-based ionic liquids catalyzed by $\mathrm{UV}-\mathrm{H}_{2} \mathrm{O}_{2}$ in water. Due to the synergistic effect of $\mathrm{UV}$ and $\mathrm{H}_{2} \mathrm{O}_{2}$, the degradation efficiency can be significantly improved compared to any of them alone. Fitting results showed that the degradation reaction follows pseudo-first-order kinetics and reaction rate constants with hydroxyl radicals ranging from $0.0005 \mathrm{~s}^{-1}$ to $0.0529 \mathrm{~s}^{-1}$. The experimental data showed that satisfactory results can be obtained at a temperature of $45^{\circ} \mathrm{C}$, an initial concentration of ionic liquid of $0.1 \mathrm{M}$, and a hydrogen peroxide concentration of $0.1 \mathrm{M}$. We also explored the effects of chloride ions and $\mathrm{pH}$ on degradation reactions. In an appropriate situation, the degradation yield of $\left[\mathrm{C}_{4} \mathrm{Bth}\right] \mathrm{PF}_{6}$ could achieve $97 \%$ in $60 \mathrm{~min}$ and $99 \%$ in $90 \mathrm{~min}$. The $\mathrm{UV}-\mathrm{H}_{2} \mathrm{O}_{2}$ combination process could provide an effective technique for the treatment of benzothiazolium-based ionic liquids in wastewater.
\end{abstract}

Keywords: photocatalysis; degradation; benzothiazole ionic liquid; $\mathrm{H}_{2} \mathrm{O}_{2}$

\section{Introduction}

Ionic liquids (ILs) are considered to be good substitutes for organic solvents with low vapor pressure and low flammability [1] and are widely used in various fields [2,3]. However, their toxicity has been paid more attention in recent years $[4,5]$. Benzothiazole ILs have been synthesized and have wide applications in synthesis [6], extraction [7], and separation [8,9]. It has been shown that benzothiazole ILs have toxic effects on zebrafish, especially in acidic environments [10]. Most ILs are relatively stable and toxic, so the efficiency of natural degradation is very low [11,12]. ILs are likely to become persistent pollutants and cause long-term damage to the ecological environment if discharged without treatment. There are few studies on the degradation of benzothiazole ILs. Therefore, it is of great significance to study methods for their effective treatment in wastewater.

The recovery methods of ILs in wastewater include extraction [13], adsorption [14,15], and membrane separation [16,17], but these methods cannot completely remove low-concentration ILs in wastewater. Degradation is considered to be an available method for the low-concentration ILs $[18,19]$. At present, there are many degradation methods, such as photodegradation $[19,20]$, chemical oxidation [21,22], electrochemical oxidation [23,24], biodegradation [25], and thermal decomposition [26]. Thermal decomposition and biodegradation have certain limitations due to 
stable chemical structure and toxicity of ILs [12]. Electrochemical oxidation avoids the use of oxidants, but it is often necessary to add a suitable electrolyte into the aqueous IL solution to increase the conductivity of the solution, while electrolyte electrolysis may cause secondary contamination [27]. At present, photodegradation [28] and chemical oxidation are the most concerned methods for IL degradation. Previous studies have shown that photocatalysis can effectively degrade ILs. Complete degradation of ionic liquids (organic cations: $\mathrm{BMIM}$ and EMIM; inorganic anions: $\mathrm{BF}_{4}{ }^{-}, \mathrm{PF}_{6}{ }^{-}$, and $\mathrm{Br}^{-}$) can be achieved by combining hydrothermal and photocatalytic treatment [19]. Dye-sensitized photocatalysts (DCQ- $\mathrm{TiO}_{2} / \mathrm{SiO}_{2}$ ) have also been used to degrade imidazolium-based ionic liquids. The experimental results show that the synthesized photocatalyst has higher activity. Under the experimental conditions, the degradation rate of [BMIM]Br reached $95 \%$ at 180 minutes, and the photodegradation intermediate was identified as a harmless and easily biodegradable component [29]. Photocatalytic degradation is much faster than natural degradation (half-lives of IL cations ranged from $32 \pm 4$ to $135 \pm 25$ days) [11].

In this study, low concentrations of benzothiazole ILs aqueous solutions were used as experimental objects for exploring a simple and effective method for the treatment of these ILS. Influence conditions of the degradation process and the degradation kinetics were studied.

\section{Materials and Methods}

All chemicals involved in this paper were at least analytically pure. The methanol used in HPLC was chromatographic grade and purchased from Chengdu Kelong Chewed Reagent Factory (Chengdu, China). Sodium chloride and sodium hydroxide were purchased from Chengdu Chron Chemicals Co., Ltd. (Chengdu, China). Benzothiazole was purchased from Shanghai Titan Technology Co., Ltd. (Shanghai, China). Potassium hexafluorophosphate, sodium tetrafluoroborate, 1-bromo-n-propane, 1-bromo-n-butane, 1-bromopentane, and 1-bromo-n-hexane were purchased from Shanghai Aladdin Biochemical Technology Co., Ltd. (Shanghai, China). The synthesis method and purity of benzothiazolium-based ILs are shown in Figures S1 and S2. Dichloromethane, silver nitrate, and absolute ethanol were purchased from Chengdu Kelong Chemical Reagent Factory.

The experimental equipment for ultraviolet photocatalytic degradation of benzothiazole IL was an XH-300UL microwave ultrasonic ultraviolet photocatalytic synthesizer from Beijing Xianghu Technology Development Co., Ltd (Beijing, China). The UV wavelength used in the experiments was $365 \mathrm{~nm}$, power was $250 \mathrm{~W}$, and illumination was $5 \mathrm{~mW} \mathrm{~cm}^{-2}$. The light intensity was measured by its own ultraviolet radiation meter. In all experiments, we fixed the wavelength and intensity of ultraviolet light to explore the effect of other conditions on degradation response. The $\mathrm{pH}$ meter was supplied by Shanghai Yulong Instrument Co., Ltd. (Shanghai, China). The vacuum drying oven was provided by Gongyi Yuhua Instrument Co., Ltd. (Henan, China). The pure water machine was purchased from Sichuan Ulpure Technology Co., Ltd. (Chengdu, China) and the model of the pure water machine is UPH-I-10T.

The kinetic constant was obtained by simulating the concentration versus time function, and the kinetic rate constants under different conditions were compared.

HPLC analysis was performed using an LC system (Shimadzu, Kyoto, Japan) equipped with an LC-20AT pump and an HCT-360 LC column cooler/heater (Hengao Tech \& Dev, Tianjin, China) coupled to an SPD-M20A PDA detector working at $278 \mathrm{~nm}$. Separation was carried out using a Symmetry C18 column (Waters, Massachusetts, USA) of $4.6 \times 250 \mathrm{~mm}, 5 \mu \mathrm{m}$, and thermostated at $30^{\circ} \mathrm{C}$ using a $40 / 60$ $(v / v$ methanol: water) mixture as mobile phase with a flow-rate of $1 \mathrm{~mL}$ min. Class-VP workstation (Shimadzu, Kyoto, Japan) was used for data acquisition. 


\section{Results}

\subsection{Degradation Process Kinetics}

We studied the degradation kinetics of benzothiazole ILs, which can reflect the change of ionic liquid concentration over time. Consequently, we can estimate the average half-life of ILs in aqueous solution and compare the degradation rates under different conditions intuitively. The calculation results are shown in Figure 1. It can be seen from the curve of the concentration of the reactants over time that the degradation reaction follows the pseudo-first-order kinetics and can be expressed in Equation (1). The rate constants for all cases are shown in Table S1.

$$
\ln \left(c / c_{0}\right)=k t,
$$
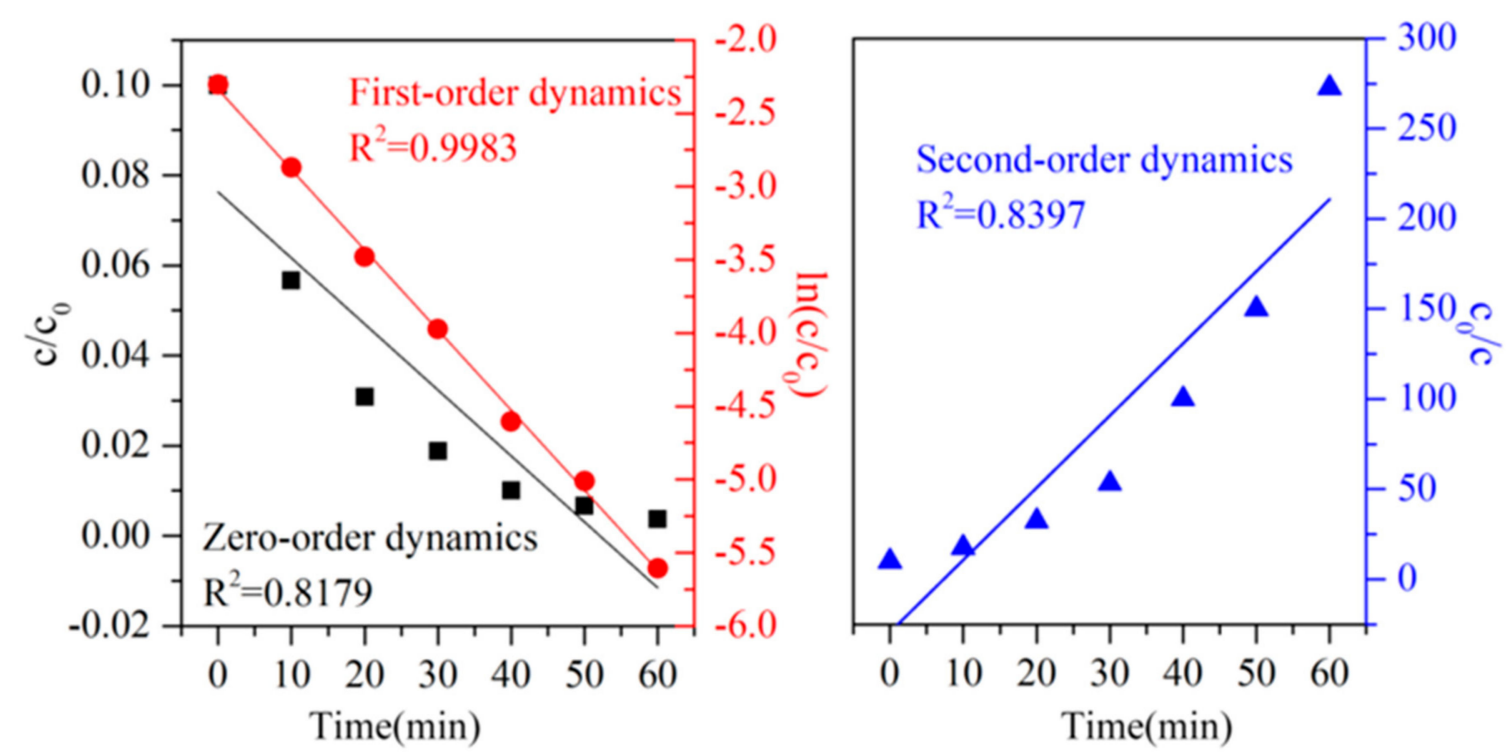

Figure 1. Kinetic simulation of degradation of benzothiazole ILs; $\left[\mathrm{C}_{4} \mathrm{BthPF}_{6}\right]=0.1 \mathrm{mM}, \mathrm{t}=45^{\circ} \mathrm{C}, \mathrm{pH}=$ 5.06, $\left[\mathrm{H}_{2} \mathrm{O}_{2}\right]=100 \mathrm{mM}$.

\subsection{Effect of the Concentration of Hydrogen Peroxide on Degradation}

Hydrogen peroxide is the main hydroxyl radical provider, so its initial concentration will naturally affect the degradation efficiency. An appropriate amount of hydrogen peroxide was added to the solution. The obtained results are shown in Figure 2. When the concentration of $\mathrm{H}_{2} \mathrm{O}_{2}$ is between 50 $\mathrm{mM}$ and $100 \mathrm{mM}$, the higher the concentration of $\mathrm{H}_{2} \mathrm{O}_{2}$, and the faster the $\left[\mathrm{C}_{4} \mathrm{Bth}_{\mathrm{P}} \mathrm{PF}_{6}\right.$ degrades. When the concentration of $\mathrm{H}_{2} \mathrm{O}_{2}$ is in the range of $100 \mathrm{mM}$ to $150 \mathrm{mM}$, the concentration of $\mathrm{H}_{2} \mathrm{O}_{2}$ continues to increase and the degradation yield decreases. $\left[\mathrm{C}_{4} \mathrm{Bth}\right] \mathrm{PF}_{6}$ has the fastest degradation rate when the concentration of $\mathrm{H}_{2} \mathrm{O}_{2}$ is $100 \mathrm{mM}$ and the half-life of ionic liquids is $12 \mathrm{~min}$. Continuing to increase the concentration of hydrogen peroxide does not always increase the yield of degradation because excessive concentration of hydrogen peroxide often leads to the "automatic scavenging reaction" as shown in the following equations (Equations (2)-(5)), which leads to the removal of oxidized hydroxyl radicals [30].

$$
\begin{gathered}
\mathrm{H}_{2} \mathrm{O}_{2}+\mathrm{hv} \rightarrow 2^{\cdot} \mathrm{OH}, \\
\mathrm{H}_{2} \mathrm{O}_{2}+\mathrm{OH} \rightarrow \mathrm{HO}_{2}{ }^{\cdot}+\mathrm{H}_{2} \mathrm{O}, \\
\mathrm{HO}_{2}+\mathrm{OH} \rightarrow \mathrm{O}_{2}+\mathrm{H}_{2} \mathrm{O}, \\
\mathrm{HO}_{2} \rightarrow \mathrm{O}_{2} \cdot{ }^{-}+\mathrm{H}^{+},
\end{gathered}
$$

Therefore, considering both degradation efficiency and economy, a suitable initial concentration of hydrogen peroxide is $100 \mathrm{mM}$. 
(a)

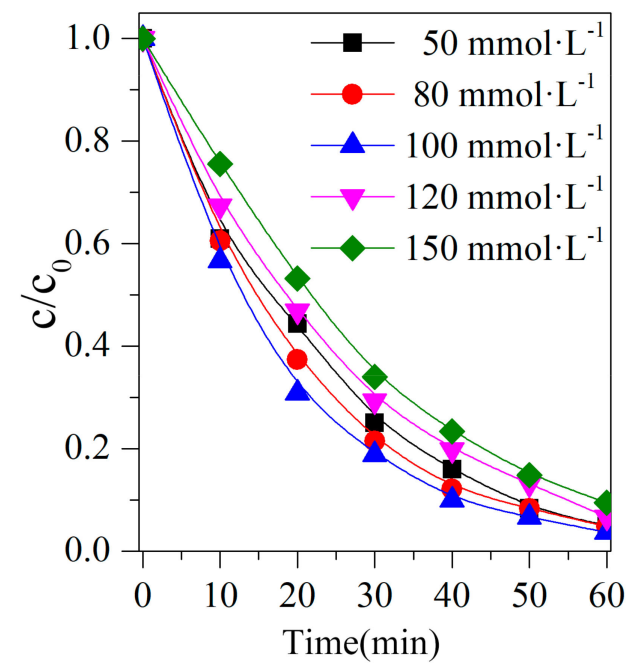

(b)

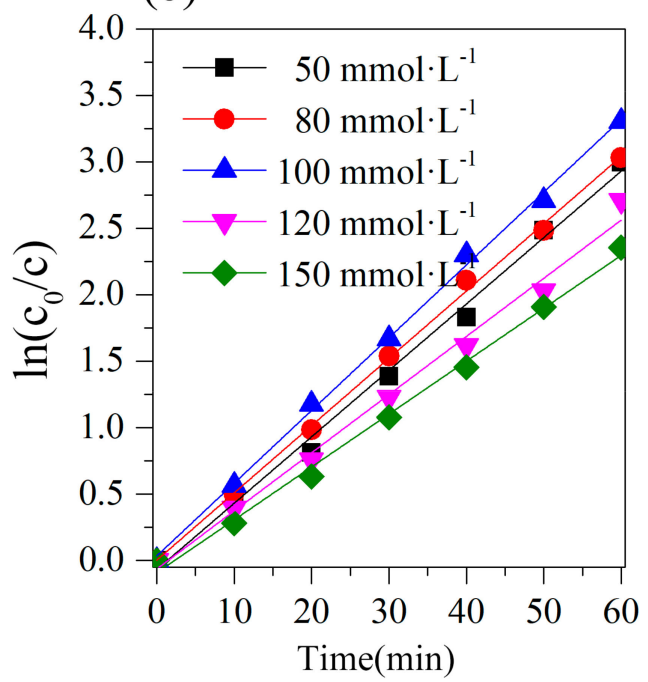

Figure 2. Effect of concentration of hydrogen peroxide (a); effect of concentration of hydrogen peroxide (b) on kinetic constant; $\left[\mathrm{C}_{4} \mathrm{BthPF}_{6}\right]=0.1 \mathrm{mM}, \mathrm{t}=45^{\circ} \mathrm{C}, \mathrm{pH}=5.06$.

\subsection{Effect of Initial Concentration of ILs on Degradation}

As mentioned above, the reaction is a first-order kinetic reaction, and half-life of ILs should not be related to the initial concentration of the reactant. However, under fixed illumination intensity, ionic liquids can also absorb a part of ultraviolet light, which leads to the reduction of ultraviolet absorption of hydrogen peroxide. The final result is a reduction in the reaction rate. Therefore, we investigated the effect of ionic liquid concentration on the degradation rate. IL solutions of $0.05,0.10,0.15$, and $0.20 \mathrm{mM}$ were prepared. Experiments were carried out in the condition of $100 \mathrm{mM}$ hydrogen peroxide and $45^{\circ} \mathrm{C}$. Experimental results showed that the degradation yield gradually decreased with the increase of the concentration of IL. It can be seen from Figure 3 that when the IL concentration is less than $0.1 \mathrm{mM}$, the IL degradation yield is less increased. When the concentration is greater than $0.1 \mathrm{mM}$, the degradation yield is decreased more. Therefore, the $0.10 \mathrm{mM}$ could be considered as an optimum initial IL concentration.

(a)

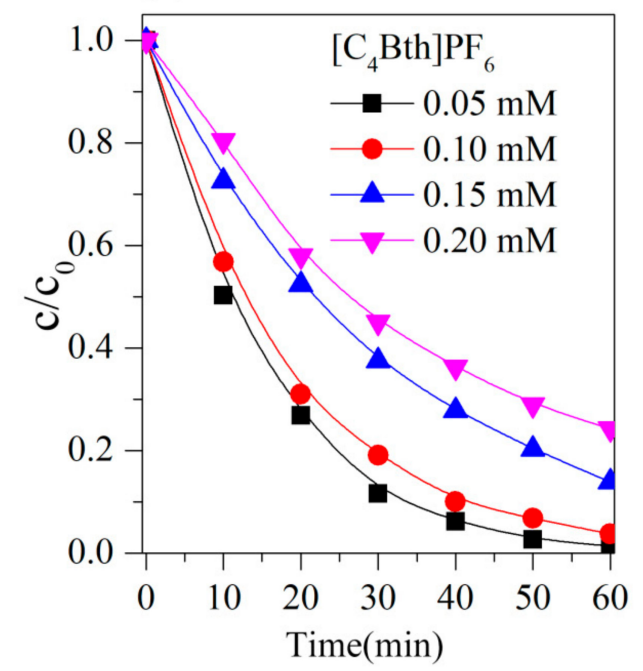

(b)

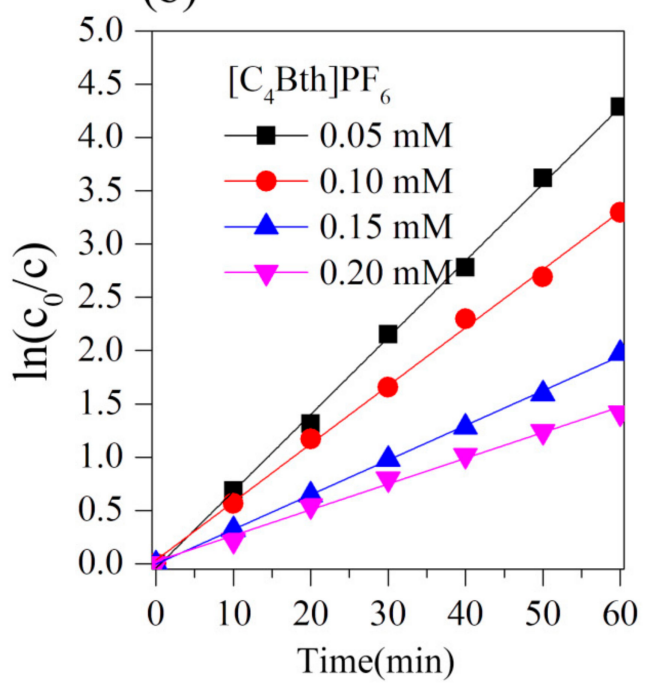

Figure 3. Effect of concentration of initial concentration of ionic liquids (ILs) on degradation (a); effect of initial concentration of ILs $(\mathbf{b})$ on kinetic constant; $t=45^{\circ} \mathrm{C}, \mathrm{pH}=5.06,\left[\mathrm{H}_{2} \mathrm{O}_{2}\right]=100 \mathrm{mM}$. 


\subsection{Effect of Temperature on Degradation}

On the basis of the Vant Hoff rule, the higher the temperature is, the higher the reaction rate will be. In this paper, the activity of hydroxyl radicals does increase with the rise of temperature, but hydrogen peroxide, which produces hydroxyl radicals, decomposes into oxygen and water more quickly, resulting in a decrease in the concentration of hydroxyl radicals. The degradation of $0.1 \mathrm{mM}$ $\left[\mathrm{C}_{4} \mathrm{Bth}\right] \mathrm{PF}_{6}$ was investigated in the condition of $100 \mathrm{mM} \mathrm{H}_{2} \mathrm{O}_{2}$ and $\mathrm{pH} 5.06$ for different temperatures $25^{\circ} \mathrm{C}, 35^{\circ} \mathrm{C}, 45^{\circ} \mathrm{C}, 55^{\circ} \mathrm{C}$, and $65^{\circ} \mathrm{C}$. The experimental results are shown in Figure 4 . The IL degradation yield increases with the increase of temperature when the system temperature is lower than $45^{\circ} \mathrm{C}$. When the temperature is greater than $45^{\circ} \mathrm{C}$, the situation is reversed.

(a)

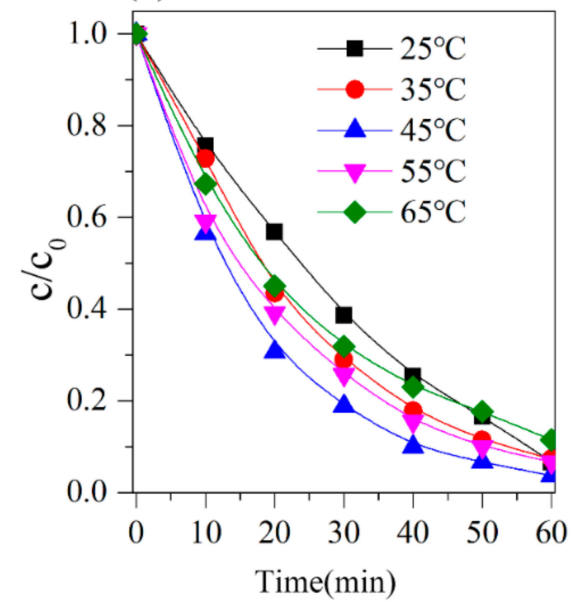

(b)

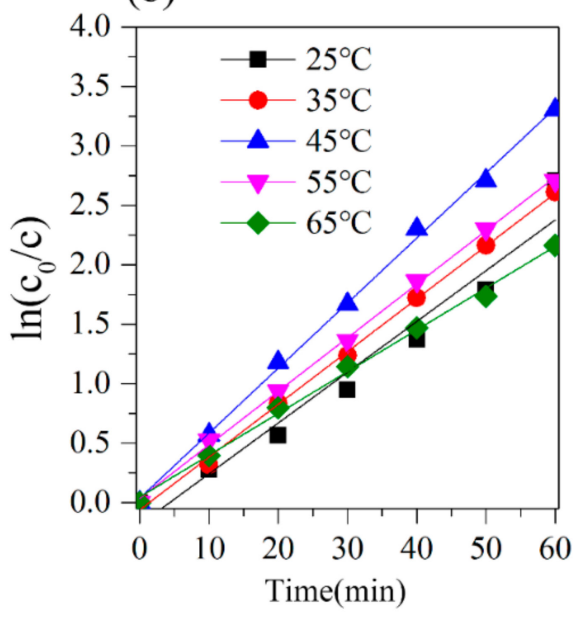

Figure 4. Effect of temperature on degradation (a); effect of temperature (b) on kinetic constant; $\left[\mathrm{C}_{4} \mathrm{BthPF}_{6}\right]=0.1 \mathrm{mM}, \mathrm{pH}=5.06,\left[\mathrm{H}_{2} \mathrm{O}_{2}\right]=100 \mathrm{mM}$.

\subsection{Effect of Chloride Ion Concentration on Degradation}

Chloride ions can react with hydroxyl radicals to form chlorine-containing inorganic radical ions (Equations (6)-(10)). The chlorine-containing radical ion can further generate chlorine radicals. The reactivity of chlorine radicals is much smaller than that of hydroxyl radicals. Chloride ions and chlorine radicals further generate dichloro radicals. Finally, the generated chlorine molecules terminate the transfer of free radicals [31]. Chloride ions are widely found in ocean and river water and also in industrial wastewaters, so the effect of chloride ion concentration on oxidative degradation was considered in this study.

Different concentration levels of $\mathrm{NaCl}$ were added to an aqueous solution containing $0.1 \mathrm{mM} \mathrm{IL}$ and $100 \mathrm{mM} \mathrm{H}_{2} \mathrm{O}_{2}$ to make chloride anion concentrations of $0.001 \mathrm{M}, 0.01 \mathrm{M}$, and $0.1 \mathrm{M}$. The photo-assisted oxidation reaction was carried out in a water bath at a temperature of $45^{\circ} \mathrm{C}$. The results are shown in Figure $5 \mathrm{a}$, where it can be seen from the figure that the chloride ion had a significant inhibitory effect on the degradation of benzothiazole ILs and the degradation efficiency was significantly reduced when the concentration of chloride ion was only $0.001 \mathrm{M}$. The mechanism by which chloride ions inhibit the degradation reaction was as follows:

$$
\begin{gathered}
\mathrm{Cl}^{-}+\mathrm{OH} \rightarrow \mathrm{HOCl}^{-}, \\
\mathrm{HOCl}^{-}+\mathrm{H}^{+} \rightarrow \mathrm{Cl}^{-}+\mathrm{H}_{2} \mathrm{O}, \\
\mathrm{Cl}^{-}+\mathrm{Cl}^{-} \rightarrow \mathrm{Cl}_{2}^{--} \\
2 \mathrm{Cl}_{2}^{\cdot-} \rightarrow 2 \mathrm{Cl}^{-}+\mathrm{Cl}_{2}(\mathrm{aq}) \\
2 \mathrm{Cl}^{\cdot} \rightarrow \mathrm{Cl}_{2}
\end{gathered}
$$


(a)

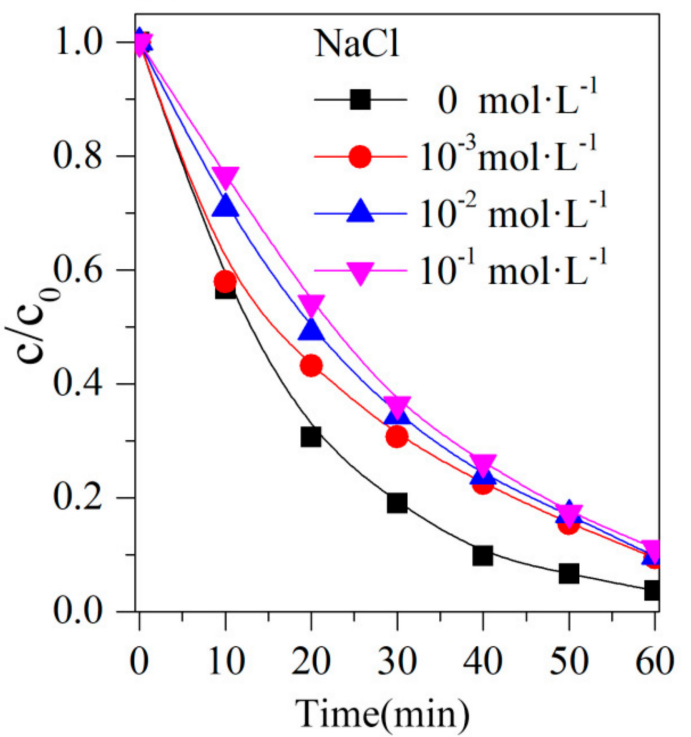

(b)

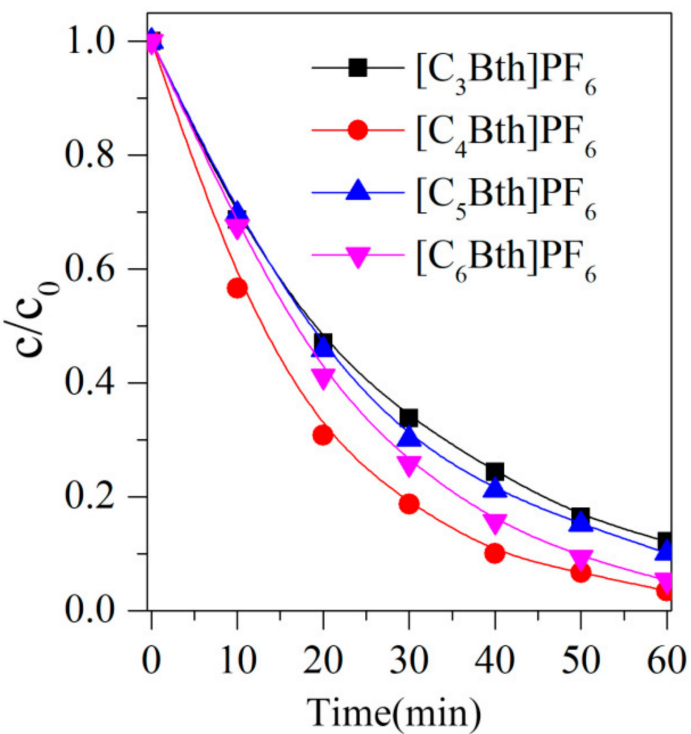

Figure 5. Effect of chloride ion concentration on degradation (a) and carbon chain length of ILs (b) on degradation; $[\mathrm{IL}]=0.1 \mathrm{mM}, \mathrm{t}=45^{\circ} \mathrm{C},\left[\mathrm{H}_{2} \mathrm{O}_{2}\right]=100 \mathrm{mM}$.

\subsection{Effect of Length of Side Chain on Degradation}

ILs of different carbon chain lengths were prepared into aqueous solutions of $0.1 \mathrm{mM}$ concentration. The degradation was investigated in the condition of hydrogen peroxide $100 \mathrm{mM}$ and $45^{\circ} \mathrm{C}$. As can be seen from Figure $5 b$, the degradation yields of the four ILs are sorted from fast to slow: $\left[\mathrm{C}_{4} \mathrm{Bth}_{\mathrm{PF}}>\right.$ $\left[\mathrm{C}_{6} \mathrm{Bth}\right] \mathrm{PF}_{6}>\left[\mathrm{C}_{5} \mathrm{Bth}\right] \mathrm{PF}_{6}>\left[\mathrm{C}_{3} \mathrm{Bth}\right] \mathrm{PF}_{6}$ and the yield of degradation is not directly related to the length of the carbon chain.

\subsection{Effect of Initial pH of IL Solution on Degradation}

The $\mathrm{pH}$ of the $\left[\mathrm{C}_{4} \mathrm{Bth}_{\mathrm{PF}}\right.$ aqueous solution was adjusted to 1, 3, 5.06 (natural $\mathrm{pH}$ ), 7, 9, and 11 . The result is shown in Figure 6. The experimental results show that when the $\mathrm{pH}$ is in the lower interval ( $\mathrm{pH}=1 \sim 7)$, the higher the $\mathrm{pH}$, the faster the IL degradation yield. In contrast, when the $\mathrm{pH}$ is in a high range ( $\mathrm{pH}=7$ to 11 ), the higher the $\mathrm{pH}$, the slower the degradation yield. In fact, changes in $\mathrm{pH}$ produce two relative effects. On the one hand, at higher $\mathrm{pH}$, the $\mathrm{H}_{2} \mathrm{O}_{2}$ molar absorption coefficient is larger, which is conducive to promoting the reaction and producing ${ }^{\bullet} \mathrm{OH}$. On the other hand, it is also possible to remove ${ }^{\bullet} \mathrm{OH}$ by the following reaction.

$$
\mathrm{HO}_{2}^{-}+\mathrm{OH} \rightarrow \mathrm{HO}_{2}{ }^{-}+\mathrm{OH}^{-},
$$




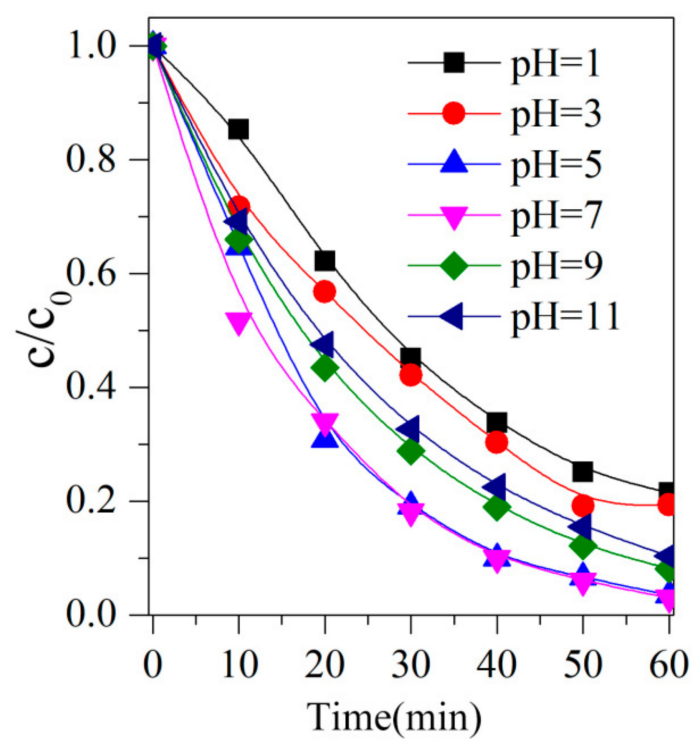

Figure 6. Effect of $\mathrm{pH}$ on degradation; $[\mathrm{IL}]=0.1 \mathrm{mM}, \mathrm{t}=45^{\circ} \mathrm{C},\left[\mathrm{H}_{2} \mathrm{O}_{2}\right]=100 \mathrm{mM}$.

When the $\mathrm{pH}$ is at a higher level $(\mathrm{pH}=7 \sim 11)$, the removal yield of $\bullet \mathrm{OH}$ is greater than the production yield, and the ILs degradation efficiency is reduced. Therefore, a neutral or weakly acidic solution is more suitable for the $\mathrm{UV}-\mathrm{H}_{2} \mathrm{O}_{2}$ oxidative degradation reaction. When the concentration of $\left[\mathrm{C}_{4} \mathrm{Bth}\right] \mathrm{PF}_{6}$ is $0.1 \mathrm{mM}$, its value of $\mathrm{pH}$ is 5.06 , which is weakly acidic, and the $\mathrm{pH}$ is not further adjusted in consideration of the economy. However, according to the existing literature, in the process of photocatalytic degradation of ILs by $\mathrm{UV}-\mathrm{H}_{2} \mathrm{O}_{2}$, alkaline solution is more favorable for this process than an acidic solution. In the process of $\mathrm{pH}$ changing from acid to alkaline, the degradation rate of ionic liquid rises in a straight line. The degradation rate first increased slowly, then decreased, and then increased rapidly. The degradation rate of methylimidazolium ILs under natural $\mathrm{pH}$ is much lower than that under alkaline conditions [30], but the degradation rate of benzothiazolium ILs may be different from that of methylimidazolium ILs.

\subsection{Photodegradation Reaction Kinetics}

In this paper, we examined seven factors that may have impacts on the degradation rate and they are hydrogen peroxide concentration, ionic liquid concentration, temperature, $\mathrm{pH}$, side chain length, and chloride ion concentration. Combined with the degradation rate constant and the half-life of the ionic liquid, we found that the ionic liquid concentration $\left(c_{0}\right)$, temperature $(T)$, and hydrogen peroxide concentration $(G)$ have a clear mathematical relationship with the rate constant within a certain range, and the rest of the conditions are not. Therefore, the power exponent equation (Equation (12)) is used to represent the change of ILs content over time during degradation. The specific calculation methods are shown in Figure S3.

$$
k=f\left(G, c_{0}, T\right)=\varepsilon G^{a} c_{0}^{b} T^{c},
$$

We perform a regression analysis of the rate constant $k$ and the hydrogen peroxide concentration (50 150 mM) to obtain the relationship between $k$ and hydrogen peroxide concentration $(G)$.

$$
\begin{gathered}
k=k_{1} G^{a}, \\
\ln k=\ln k_{1}+a \ln G,
\end{gathered}
$$

In Equation (13), $k_{1}$ and $a$ are constants. When the concentration of hydrogen peroxide is in the range of 50 100 mM, $\ln k$ is plotted on the abscissa and $\ln G$ is plotted on the ordinate. We can calculate the values of $k_{1}$ and $a$.

$$
k=0.02260 G^{0.1900,}
$$


Similar to the above method of calculation, when the IL concentration is in the range of 0.05 to $0.20 \mathrm{mM}$, the values of $k$ and $b$ can be calculated as follows:

$$
k=0.0071 c_{0}{ }^{-0.8063},
$$

When the temperature is between 25 and $45^{\circ} \mathrm{C}$, the values of $k$ and $T$ can be calculated as follows:

$$
k=0.00369 T^{0.7037},
$$

In this paper, the total reaction kinetic constant could be expressed by a power exponential equation (Equation (18)). When $\mathrm{pH}=5.06, \mathrm{~T}=45^{\circ} \mathrm{C}, \mathrm{G}=100 \mathrm{mM}$, and $c_{0}=0.1 \mathrm{M}$; the value of $\varepsilon$ can be found to be $2.44 \times 10^{-4}$. Therefore, the general equation can be written as

$$
k=2.44 \times 10^{-4} G^{0.1900} c_{0}{ }^{-0.8063} T^{0.7037},
$$

The influence of three factors on the degradation of benzothiazole ILs from strong to weak was: initial concentration of IL $\left(c_{0}\right)>$ temperature $(T)>$ concentration of hydrogen peroxide $(G)$. Moreover, hydrogen peroxide concentration, temperature, and degradation rate constant are positively correlated, while ionic liquid concentration is negatively correlated.

\subsection{Effect of Different Degradation Methods on Kinetic Constant}

The degradation catalyzed with a UV light, a hydrogen peroxide alone, and a combination of UV and hydrogen peroxide are compared (the obtained results are shown in Figure 7). It can be seen from the kinetic constant that the combination $\left(\mathrm{k}_{\mathrm{UV}-\mathrm{H} 2 \mathrm{O} 2}=0.0562 \mathrm{~min}^{-1}, \mathrm{t}_{1 / 2}=12 \mathrm{~min}\right)$ is much greater than that of anyone alone $\left(\mathrm{k}_{\mathrm{UV}}=0.0026 \mathrm{~min}^{-1}, \mathrm{t}_{1 / 2}=266 \mathrm{~min}, \mathrm{k}_{\mathrm{H} 2 \mathrm{O} 2}=0.0005 \mathrm{~min}^{-1}, \mathrm{t}_{1 / 2}=1386 \mathrm{~min}\right)$, which means the $\mathrm{UV}-\mathrm{H}_{2} \mathrm{O}_{2}$ system is much more efficient. This is because UV can promote the conversion of hydrogen peroxide to hydroxyl radicals (Equation (2)).

(a)

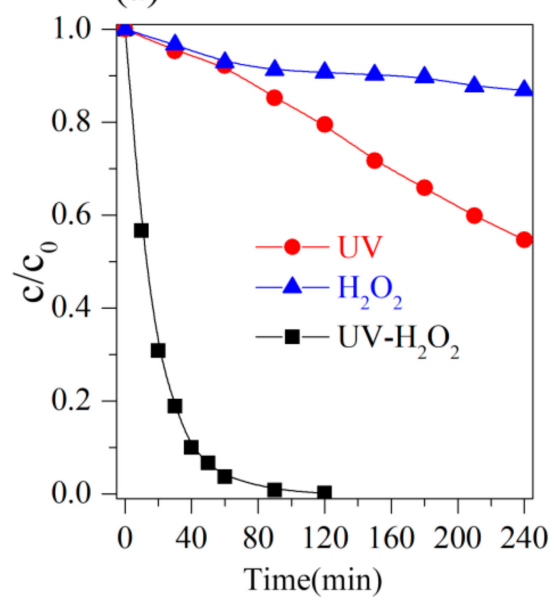

(b)

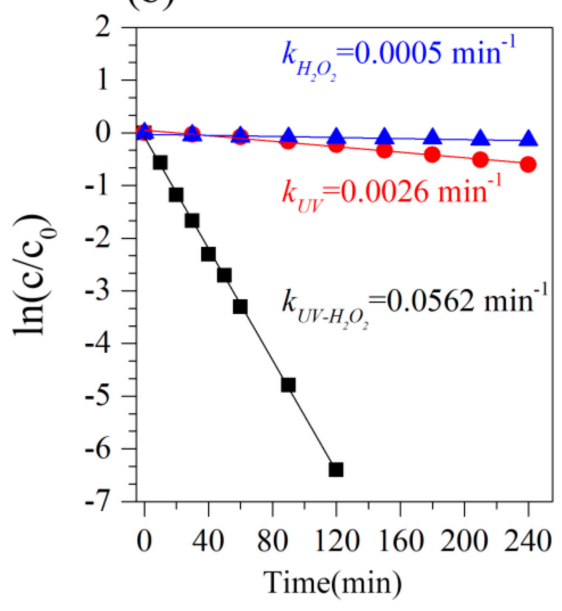

Figure 7. Effect of different methods (a) on degradation; effect of different methods (b) on the rate constant of degradation kinetics; $\left[\mathrm{C}_{4} \mathrm{BthPF}_{6}\right]=0.1 \mathrm{mM}, \mathrm{t}=45^{\circ} \mathrm{C}, \mathrm{pH}=5.06,\left[\mathrm{H}_{2} \mathrm{O}_{2}\right]=100 \mathrm{mM}$.

\section{Conclusions}

The degradation of benzothiazole ILs in wastewater could be achieved satisfactorily with UV, $\mathrm{H}_{2} \mathrm{O}_{2}$, and $\mathrm{UV}-\mathrm{H}_{2} \mathrm{O}_{2}$. The degradation reaction in the $\mathrm{UV}-\mathrm{H}_{2} \mathrm{O}_{2}$ system exhibits the most efficiency and accords a pseudo-first-order kinetic. The influence of three main factors on the degradation from strong to weak was: initial concentration of IL, temperature, and amount of oxidant. In addition, the anion property of ILs has a significant effect on the degradation and chloride ion in the reaction 
environment and can significantly reduce the degradation yield. This study could prove an alternative way to treat low concentrations of benzothiazole ILs in wastewater.

Supplementary Materials: The following are available online at http://www.mdpi.com/2076-3417/10/3/894/s1. Figure S1. The synthesis procedure of benzothiazole-based ionic liquids; Figure S2. HPLC chromatogram of six benzothiazolium-based ionic liquids; Figure S3. Effect of concentration of ILs on degradation (a); Effect of concentration of ILs on kinetic constant (b); Degradation kinetic constants corresponding to different concentrations of ILs (c); Linear fit of lnk and $\operatorname{lnc}_{0}$ (d); Table S1. Degradation rate constant $k$ under different conditions.

Author Contributions: Conceptualization, H.S. and M.Z.; methodology, H.Z. and Y.S.; validation, J.G., H.Z., and X.W.; formal analysis, J.G.; writing—original draft preparation, J.G.; writing—review and editing, H.S.; visualization, S.Y.; supervision, M.Z. All authors have read and agreed to the published version of the manuscript.

Funding: This research received no external funding.

Conflicts of Interest: The authors declare no conflicts of interest.

\section{References}

1. Rogers, R.D.; Seddon, K.R. CHEMISTRY: Ionic Liquids-Solvents of the Future? Science 2003, 302, 792-793. [CrossRef]

2. Sowmiah, S.; Srinivasadesikan, V.; Tseng, M.-C.; Chu, Y.-H. On the Chemical Stabilities of Ionic Liquids. Molecules 2009, 14, 3780-3813. [CrossRef]

3. Nagy, B.; Bakos, I.; Geissler, E.; László, K. Water-Ionic Liquid Binary Mixture Tailored Resorcinol-Formaldehyde Carbon Aerogels without Added Catalyst. Materials 2019, 12, 4208. [CrossRef]

4. Richardson, S.D.; Ternes, T.A. Water analysis: Emerging contaminants and current issues. Anal. Chem. 2011, 83, 4614-4648. [CrossRef]

5. Calza, P.; Vione, D.; Fabbri, D.; Aigotti, R.; Medana, C. Imidazolium-based ionic liquids in water: Assessment of photocatalytic and photochemical transformation. Environ. Sci. Technol. 2015, 49, 10951-10958. [CrossRef] [PubMed]

6. Barhdadi, R.; Maekawa, H.; Comminges, C.; Troupel, M. Catalytic electrosynthesis in ionic liquid: Performance of nickel-(2,2'-bipyridine) complexes for production of aryl propan-2-ones. Chem. Soc. Jpn. 2009, 82, 1510-1513. [CrossRef]

7. Ma, S.; Funaki, K.; Miyazaki, A.; Muramatsu, A.; Kanie, K. Ionic Liquids with Amino Moieties: Selective and Reversible Extraction/Back-Extraction for Platinum-Group Metal Ions from Aqueous Solutions. Chem. Lett. 2017, 46, 1422-1425. [CrossRef]

8. Feng, X.; Song, H.; Dong, B.; Yang, Y.; Yao, S. Sequential extraction and separation using ionic liquids for stilbene glycoside and anthraquinones in polygonum multiflorum. J. Mol. Liq. 2017, 241, 27-36. [CrossRef]

9. Torralba-Calleja, E.; Skinner, J.; Gutiérrez-Tauste, D. $\mathrm{CO}_{2}$ capture in ionic liquids: A review of solubilities and experimental methods. J. Chem. 2013, 2013, 1-16. [CrossRef]

10. Chen, Y.; Luo, Y.; Yang, X.; Yao, S.; Song, H. Toxic effect of benzothiazole ionic liquids on antioxidation mechanism of zebrafish. Chem. Ind. Eng. Proc. 2016, 35, 2.

11. Pati, S.G.; Arnold, W.A. Photochemical transformation of four ionic liquid cation structures in aqueous solution. Environ. Sci. Technol. 2017, 51, 11780-11787. [CrossRef] [PubMed]

12. Jordan, A.; Gathergood, N. Biodegradation of ionic liquids-A critical review. Chem. Soc. Rev. 2015, 44, 8200-8237. [CrossRef] [PubMed]

13. Scurto, A.M.; Aki, S.N.V.K.; Brennecke, J.F. Carbon dioxide induced separation of ionic liquids and water. Chem. Commun. 2003, 5, 572-573. [CrossRef] [PubMed]

14. Palomar, J.; Lemus, J.; Gilarranz, M.A.; Rodriguez, J.J. Adsorption of ionic liquids from aqueous effluents by activated carbon. Carbon 2009, 47, 1846-1856. [CrossRef]

15. Li, X.; Li, S.; Wang, F.; Xi, H.; Wang, L. Adsorption of [bmim]cl ionic liquid by acid-Modified bentonite. Chinese. J. Chem. Eng. 2007, 58, 1489-1493.

16. Liu, X.; Wang, W. The application of nanofiltration technology in recovery of ionic liquids from spinning wastewater. AMM 2012, 178-181, 499-502. [CrossRef]

17. Haerens, K.; Van Deuren, S.; Matthijs, E.; Van der Bruggen, B. Challenges for recycling ionic liquids by using pressure driven membrane processes. Green Chem. 2010, 12, 2182. [CrossRef] 
18. Li, X.; Zhao, J.; Li, Q.; Wang, L.; Tsang, S.C. Ultrasonic chemical oxidative degradations of 1,3-dialkylimidazolium ionic liquids and their mechanistic elucidations. Dalton Trans. 2007, 19, 1875. [CrossRef]

19. Itakura, T.; Hirata, K.; Aoki, M.; Sasai, R.; Yoshida, H.; Itoh, H. Decomposition and removal of ionic liquid in aqueous solution by hydrothermal and photocatalytic treatment. Environ. Chem. Lett. 2009, 7, 343-345. [CrossRef]

20. Esplugas, S.; Giménez, J.; Contreras, S.; Pascual, E.; Rodriguez, M. Comparison of different advanced oxidation processes for phenol degradation. Water Res. 2002, 36, 1034-1042. [CrossRef]

21. Siedlecka, E.M.; Mrozik, W.; Kaczyński, Z.; Stepnowski, P. Degradation of 1-butyl-3-methylimidazolium chloride ionic liquid in a fenton-like system. J. Hazard. Mater. 2008, 154, 893-900. [CrossRef] [PubMed]

22. Siedlecka, E.M.; Stepnowski, P. The effect of alkyl chain length on the degradation of alkylimidazolium- and pyridinium-type ionic liquids in a fenton-like system. Environ. Sci. Pollut. R. 2009, 16, 453-458. [CrossRef] [PubMed]

23. Kroon, M.C.; Buijs, W.; Peters, C.J.; Witkamp, G. Decomposition of ionic liquids in electrochemical processing. Green Chem. 2006, 8, 241-245. [CrossRef]

24. Siedlecka, E.M.; Stolte, S.; Gołębiowski, M.; Nienstedt, A.; Stepnowski, P.; Thöming, J. Advanced oxidation process for the removal of ionic liquids from water: The influence of functionalized side chains on the electrochemical degradability of imidazolium cations. Sep. Purif. Technol. 2012, 101, 26-33. [CrossRef]

25. Stolte, S.; Abdulkarim, S.; Arning, J.; Blomeyer-Nienstedt, A.; Bottin-Weber, U.; Matzke, M.; Ranke, J.; Jastorff, B.; Thoming, J. Primary biodegradation of ionic liquid cations, identification of degradation products of 1-methyl-3-octylimidazolium chloride and electrochemical wastewater treatment of poorly biodegradable compounds. Green Chem. 2008, 10, 214-224. [CrossRef]

26. Mahrova, M.; Conte, M.; Roman, E.; Nevshupa, R. Critical insight into mechanochemical and thermal degradation of imidazolium-based ionic liquids with alkyl and monomethoxypoly(ethylene glycol) side chains. J. Phys. Chem. C 2014, 118, 22544-22552. [CrossRef]

27. Bocos, E.; González-Romero, E.; Pazos, M.; Sanromán, M.A. Application of electro-fenton treatment for the elimination of 1-butyl-3-methylimidazolium triflate from polluted water. Chem. Eng. J. 2017, 318, 19-28. [CrossRef]

28. Reinosa, J.J.; Docio, C.M.Á.; Ramírez, V.Z.; Lozano, J.F.F. Hierarchical nano zno-micro tio2 composites: High uv protection yield lowering photodegradation in sunscreens. Ceram Int. 2018, 44, 2827-2834. [CrossRef]

29. Huang, L.; Yu, Y.; Fu, C.; Guo, H.; Li, X. Photocatalytic degradation of imidazolium ionic liquids using dye sensitized tio2-sio2 composites. J. Roy. Soc. Med. 2017, 51, 32120-32125. [CrossRef]

30. Boutiti, A.; Zouaghi, R.; Bendjabeur, S.E.; Guittonneau, S.; Sehili, T. Photodegradation of 1-hexyl-3-methylimidazolium by uv/h2o2 and uv/tio2: Influence of ph and chloride. J. Photochem. Photobiol. A 2017, 336, 164-169. [CrossRef]

31. Li, X.; Li, F. Study of au/au(3+)-tio2 photocatalysts toward visible photooxidation for water and wastewater treatment. Environ. Sci. Technol. 2001, 35, 2381-2387. [CrossRef] [PubMed]

(C) 2020 by the authors. Licensee MDPI, Basel, Switzerland. This article is an open access article distributed under the terms and conditions of the Creative Commons Attribution (CC BY) license (http://creativecommons.org/licenses/by/4.0/). 